\title{
Brain, Creativity and Education
}

\author{
Norbert Jaušovec ${ }^{*}$ and Ksenija Jaušovec
}

Faculty of Education, University of Maribor, Slovenia

\begin{abstract}
The aim of the present paper is to answer the question: Has neuropsychology anything to say about teaching for creativity? The complexities involved in creativity suggest that there is probably no single teaching approach for its development. Creativity research has most often focused on the creative personality and on ability components, like the creative process, problem formulation and solving, the relation between intelligence and creativity. The review therefore first provides a "neuro" perspective of psychological constructs. Next the possibility of improving ability with training and neurofeedback is discussed. Finally, some suggestions for further research and implication on teaching for creativity are provided.
\end{abstract}

Keywords: Creativity, intelligence, learning, brain activity.

\section{INTRODUCTION}

The main concern of educators and educational research was, and still is the design of methods that would reduce the time and effort needed to become an expert in a domain. One could say: In the search for the "Nürnberger Trichter" - a magic funnel used to pour, almost in no time, knowledge and expertise into students. During past decades various theoretical approaches, have recommended methods that tried to facilitate the learning process. The behaviorist theory [1], for instance, has developed a technique by which responses can be reinforced immediately, known as programmed instruction (nowadays also known as the computer-assisted instruction). On the other hand, the constructivist theory [2, 3] has favored approaches like learning by discovery and cognitive apprenticeship. Over the past years the benefits of incorporating findings from cognitive neuroscience into the field of education have been vigorously discussed. The outcome is ambivalent - from total rejection to enthusiastic acceptance. In Bruer's [4, p. 4] opinion neuropsychology has little to offer to educators: "Educational applications of brain science may come eventually, but as of now neuroscience has little to offer teachers in terms of informing classroom practice". More optimistic is the position of Hunt [5], suggesting that new technologies such as functional magnetic resonance imaging (fMRI) and positron emission tomography (PET) have led to recent discoveries about how the brain works, and how we learn. It is further suggested that this knowledge can help to design instructional strategies which will better match how we teach with how we know students learn. Some researchers therefore suggest that cognitive neuroscience can provide a bridge to a new science of education and learning [6-8], but also warn before so-called "brain based learning packages". Some of these contain alarming amounts of misinformation, and oversimplified, misrepresented 'neuro

*Address correspondence to this author at the University of Maribor, Faculty of Arts, Koroška 160, 2000 Maribor, Slovenia; Tel: +38641387834; Fax:+386 (0)2 2293 625; E-mail: norbert.jausovec@uni-mb.si myths', yet such packages are being used in many schools. One of the potentially most potent mechanisms to overcome such uncritical use of "brain-based programs" involves increasing scientific and cognitive neuroscience literacy amongst educators. A first step in this direction was the new journal, Mind, Brain and Education, launched by the International Mind, Brain, and Education Society in 2007. In the editorial $[9$, p. 1] the aim of the journal was described: "to bring together education, biology, and cognitive science to form the new field of mind, brain, and education".

\section{A "NEURO" EXPLANATION OF PSYCHOLOGICAL CONSTRUCTS}

Brain function could be described as consisting of distributed interactions between cortical regions united to perform a common cognitive task, or a behavior [10], a conceptualization that persists to the present day [11]. This model provides the conceptual framework that is the basis for most modern research on the relationship between behavior and brain functioning. In the last decades a great body of research has been accumulated relating brain activity with psychological constructs like intelligence, personality and creativity.

\section{Intelligence}

Intelligence represents the individual's overall level of intellectual ability. It serves as a general concept that includes several groups of mental abilities. One of the most influential divisions of intelligence splits it into verbal, performance and social intelligence [12]. In the recent years the term social intelligence has been replaced by emotional intelligence - the ability to recognize emotion, reason with emotion and emotion-related information, and process emotional information as part of general problem-solving [13]. Neurophysiologic research $[11,14]$ has been mainly interested in the verbal and performance components of intelligence [15-18] and has, only recently paid some attention to emotional intelligence [19-21]. Most of these studies have demonstrated a negative correlation between brain activity under cognitive load and intelligence. The explanation of these findings was an efficiency theory. This 
efficiency may derive from the non-use of many brain areas irrelevant for good task performance, as well as the more focused use of specific task-relevant areas in high intelligent individuals.

It has even been suggested that high and low intelligent individuals preferentially activate different neural circuits even though no reasoning or problem solving was required $[22,23]$. Some studies have shown a specific topographic pattern of differences related to the level of intelligence. High-ability subjects made relatively greater use of parietal regions, whereas low-ability subjects relied more exclusively on frontal regions [24, 25].

More generally, these results suggest that higher-ability individuals tend to better identify strategies needed for the solution of the task at hand. It was further reported that highly intelligent subjects displayed more brain activity in the early stages of task performance, while average individuals showed a reverse pattern. This temporal distribution of brain activity suggests that cognitive processes in highly intelligent individuals are faster than in average intelligent individuals [25].

A further finding was also that neural efficiency seems to be corroborated mostly when participants work on tasks of low to medium difficulty or complexity [14]. In the study by Doppelmayr et al. [26] the expected findings of a negative relation between activation and intelligence emerged solely for the easier items of the Raven test, whereas a tendency in the opposite direction was observed for the difficult ones. It was further shown that less intelligent individuals displayed a decrease in activation from easy to difficult tasks, whereas the opposite was true for the brighter participants. It is likely that individuals with low IQ's did not even try on the harder problems, which could explain their lower activation levels compared to those with high IQ's. It could be further assumed that individuals with low IQ's have to work harder on easy problems than do individuals with higher IQ's.

Another moderating variable that influences the neural efficiency hypothesis is gender. Some recent EEG studies relating intelligence with brain activity under cognitive load have shown that males while solving numerical and figural tasks are more likely to produce cortical activation patterns which are in line with the neural efficiency hypothesis (e.g., less activation in brighter individuals), whereas in females for the same tasks no significant differences were reported [27-29]. Similar findings could be also observed for creative problem solving [30], and for emotional intelligence [31]. Perhaps the most important finding of these studies was that the inverse intelligence-activation relationship (i.e., neural efficiency) appears to be moderated by task content and individuals' sex. Males and females displayed the expected inverse IQ-activation relationship in just that domain in which they usually perform better: females in the verbal domain, and males in the visuo-spatial ability domain.

A second branch of research focuses on structural correlates of human intelligence, attempting to answer the question: "Where in the brain is intelligence?" This body of evidence has recently been synthesized by Jung and Haier [11] in the form of their so-called 'parieto-frontal integration' (P-FIT) model of intelligence. In reviewing 37 neuroimaging studies mostly on structural correlates of intelligence they tried to answer the question of how the anatomical aspects of gray matter and white matter relate topographically to intelligence. The P-FIT model suggested - contrary to the assumption of Duncan [32] that intelligence is localized in the pre-frontal cortex - that besides frontal areas of the brain also the temporal and occipital lobes are critical in early processing of sensory information which is then fed forward to the parietal cortex, wherein abstraction, and elaboration emerge. These processes are dependent upon the fidelity of underlying white matter necessary to facilitate rapid and error-free transmission of data from posterior to frontal brain regions. The main problem with the P-FIT theory is that only a very small number of discrete brain areas approach $50 \%$ of convergence across published studies employing the same neuroimaging technique $[33,34]$. When different test batteries were used to derive $G$, this also changed the brain areas related to $G$.

A recent study conducted in our laboratory [35] showed that the pattern of neuro-electric brain activity, based on power and coherence measures, opposes the theoretical concept of a one factor " $g$ " model of intelligence. An assumption which is in line with recent research on the brain intelligence relationship, which led Haier [34, p. 136] to the statement: "The results indicate that g-scores derived from different test batteries do not necessarily have equivalent neuro-anatomical substrates, suggesting that identifying a "neuro-g" will be difficult."

\section{Personality}

Personality research has been mainly concerned in identifying psychologically meaningful characteristics on which individuals reliably differ (traits). In this dimensional or variable centered approach an individual's personality is described by a profile of trait scores. In contrast, the typological, or person centered approach aims at developing a taxonomy of personality types. The individual's personality is described on the basis of their individual personality structure. Biologically based theories of personality have almost exclusively tried to find some biological bases of personality traits $[35,36]$.

Hans Eysenck and Jeffrey Gray have been among the foremost exponents of the hypothesis that personality traits provide a window on individual differences in brain functioning. Eysenck [37] identified two key components of his conceptual nervous system: reticulo-cortical and reticulolimbic circuits. The reticulo-cortical circuit controls the cortical arousal generated by incoming stimuli, whereas the reticulo-limbic circuit controls response to emotional stimuli. Extraversion-introversion (E) relates to arousability of the reticulo-cortical circuit, so that introverts are typically more aroused than extraverts. However, methodological analyses of extraversion studies [38] have illuminated two basic problems for theory testing. First, people actively seek a moderate level of arousal, so that relationships between personality and arousal may also reflect individual differences in strategies for seeking or avoiding stimulation. Second, according to Eysenck [39], increasing stimulation provokes increasing central nervous system reactivity until an optimal point is reached, beyond which inhibition and decreasing reactivity set in. Hence, introverts may be higher, lower or equal to the arousal level of extraverts according to 
complex interactions of personality type and environmental manipulation.

Neuroticism (N) was explained in terms of activation thresholds in the sympathetic nervous system or visceral brain (the limbic system). Individuals with higher scores in neuroticism had greater activation levels and lower thresholds within sub-cortical structures [40].

There exist several reviews of the relationship between raw EEG measures and E [39, 41-44]. According to Gale, several studies supported the hypothesis that introverts are higher in cortical arousal than extraverts. However, a similar number found no differences, and three studies found results that contradicted the theory. Gale argued that moderate arousal-inducing environments were the most amenable to testing the predictions of Eysenck's theory. Low arousalinducing environments resulted in paradoxical arousal, especially in extraverts. Similarly, high arousal-inducing environments (e.g., task performance demands) resulted in possible over-arousal, again especially in extraverts. Some recent studies [44-46] lend some support to Gale's theory. On the other hand, Matthews and Gilliland [44] and Zuckerman [43] have been less enthusiastic about the level of support that past EEG studies have provided for the cortical arousal hypothesis of extraversion. Although Zuckerman [43] has pointed out that studies using female subjects or equal numbers of both sexes seem more often to support Eysenck's theory.

There have been a few more recent studies that are noteworthy. Matthews and Amelang [47] reported significant correlations between personality and EEG measures which were low in magnitude, not exceeding 0.20 , but which broadly matched expectations. Smith et al. [48] reported that introverts were generally found to produce lower levels of alpha activity reflecting higher levels of arousal, but there were also complex hemisphere by gender interactions. Schmidke and Heller [49] found that neuroticism was associated with greater relative right posterior activity, whereas predicted effects for neuroticism with frontal regions, and for extraversion with brain activity were not significant. Gale et al. [50] found that extraverts were less cortically aroused than introverts, and that neuroticism was associated with larger left versus right hemisphere differences in alpha wave activity related to mood. Tran et al. [51] showed extraverted persons to be at least three times more likely to have larger peak amplitudes in frontal alpha wave activity. However, they found no association between extraversion and alpha activity in posterior regions, and there were no alpha wave activity differences found between those with high and low anxiety levels.

Gray's personality theory began as a modification to Eysenck's theory, but is now usually seen as an alternative theory [37]. Gray has proposed two major neurological systems, the behavioral inhibition and activation system (BIS/BAS). The BIS is sensitive to signals of punishment and frustrative non-reward promoting avoidance behavior, whereas the BAS is sensitive to signals of reward and goes with approach behavior. These two brain systems underlie the personality dimensions of anxiety (neurotic introversion) and impulsiveness (neurotic extraversion). Research by Knyazev $[52,53]$ revealed that BAS was positively related to delta and negatively to alpha power, whereas the BIS showed an opposite pattern of correlations. These findings suggest higher arousal in subjects high on BIS and neuroticism, and lower arousal in subjects high on BAS and extraversion.

From a psychometric perspective there has been a growing acceptance of a five-factor model of personality (FFM), incorporating two of Eysenck's dimensions $\mathrm{E}$ and $\mathrm{N}$ together with Openness to Experience $(\mathrm{O})$, Agreeableness (A) and Conscientiousness (C). Despite the growing acceptance of the FFM of personality there have been very few studies that have examined the biological basis of $\mathrm{O}, \mathrm{A}$ and C. In a preliminary study, Stough [54] showed that individuals with higher scores in $\mathrm{O}$ tend to have a greater amount of theta production. Because theta activity decreases with age, the interpretation of the authors was that respondents high on $\mathrm{O}$ may have retained a somewhat childlike wonderment and open-mindedness about their world with a willingness to explore alternative views about issues. In a recent large scale study, Tran and colleagues [55], found only mild significant correlations in the delta and theta band with $\mathrm{E}$ and $\mathrm{C}$, and fewer associations between personality and faster frequency bands.

In contrast to the dimensional, or variable-centered, approach to personality, the typological, or person-centered, approach aims at developing a taxonomy of personality types. Whereas the dimensional approach usually investigates personality dimensions in isolation, the typological approach classifies people on the basis of their individual personality structure. A recent study by Jaušovec and Jaušovec [56] showed that most robust differences between personality types were observed between types with extreme constellations of dimensions (neurotic type - low emotional intelligence and agreeableness; high neuroticism), or between types with specific combinations of dimensions (introverts with high IQ, versus extraverts with low to average IQ). These differences were also gender specific. It was further shown that the differences were much more pronounced in the parieto-occipital brain areas than in the frontal areas. Yet in another study [57] - utilizing a reverse direction of research, relating a typology of neuro-electric brain activity to personality - it was shown that the pattern of personality factors was rather homogeneous, showing no differences between respondents belonging to different clusters of neuro-electric brain activity. A finding being in line with recent research suggesting that the Big five personality factors do not constitute the simplest and broadest possible level of personality description. DeYoung et al. [58] for instance, suggested two higher order factors Stability (Emotional Stability, Agreeableness, and Conscientiousness); and Plasticity (Extraversion and Openness). One step further is the proposal put forward by Musek [59] of just one personality factor labeled as the Big One.

\section{Creativity}

In almost every domain creativity is seen as a main contributor to development and prosperity. Biology highlights the need of organisms to adapt to new environments as a must for any species to survive. This adaptability depends heavily on the creative capacity to 
provide new adequate solutions to problems never before encountered [60], hence creativity is the source of human civilizations [61]. The economic perspective signals the importance of human capital, especially the ability to handle large amounts of information and to come up with bright ideas. Thus, creativity is regarded as one of the cornerstones of economic and social progress [62].

Despite this perceived importance of creativity for the human species, scientific research of creativity, early experimental work by Gestalt psychologists on insight aside [63] has started some 60 years ago [61, 64]. Commonly as the starting point serves Joy Paul Guilford's farewell address as president of the American Psychological Association in 1950 [65]. From the beginning creativity research has encountered several major problems. To just mentioned two of them:

- Is creativity domain specific, or is it a trait that perfuses many domains [64]?

- $\quad$ Is there a reliable measure of creativity [66]?

The second question is even more important, especially for the experimental design of neuroimaging studies, relating brain activity or structure with the level of creativity, as well as the creative process (neuroimaging studies under cognitive load). Divergent production task (allowing for multiple solutions to an open-ended problem) do not necessarily guarantee creativity. Many highly creative solutions are the product of convergent thinking, like Edison's nearly algorithmic approach to inventing, or Bach's methodical way of composing hundreds of cantatas [61]. The same is true for Wallas's [67] stages of the creative process preparation, incubation, illumination, and verification. Stages as preparation and verification are probably part of any problem-solving process.

These problems become even more evident when analyzing neuroscientific studies of creativity. Recently, two review articles have tried to summarize empirical reports of creative cognition that include a neuroimaging element. Arden and colleagues [64] reviewed 45 neuroimaging studies - 28 were based on electrophysiological techniques of brain mapping and 17 were based on hemodynamic principles. The review did not include research of contiguous and relevant areas such as 'insight' or 'innovation'. The second review of Dietrich and Kanso [61] included 72 experiments reported in 63 studies. They classified studies according to the 'creativity paradigm' used: (a) studies using the paradigm of divergent thinking, (b) studies investigating the cognition of art and music, and (c) studies looking at insight events; the second criterion they used was the type of brain mapping principles employed: (a) electrophysiological and (b) hemodynamic.

Both reviewers come to the same disappointing conclusion, namely, that the data are so diverse and fragmented that they do not allow for a generalization. As stressed by Dietrich and Kanso [61] the data are so highly variegated that even weak trends are difficult to make out. This diversity is not just between studies relying on different neuroimaging techniques (e.g., EEG versus fMRI), or creativity paradigms (e.g., divergent thinking versus artistic creativity), but also within the same paradigm and neuroimaging principle used. Why this diversity? One possible explanation could be that the neuroimaging techniques used are not sensitive enough to make such a complex process as creativity visible, but measure only differences related to task modality (e.g., figural/verbal), or single cognitive process involved in creative cognition (e.g., attention, working memory, perception). This explanation seems rather unlikely. For the constructs of intelligence [11, 14] and emotional intelligence [68] a much clearer cut relation with brain activity was revealed. Another explanation could be that creativity is domain and even task specific, involving different cognitive processes, emotional states and personality types. In our view this would much more adequately explain the diversity of brain patterns observed in the reviewed studies.

There are several theories of creativity which were dominated by assumptions like the right brain dominance; greater neural connectivity; neural efficiency; prefrontal function or low arousal. The reviewed neuroimaging studies provide no undivided support for them.

Creativity, or any stage of it, is not particularly associated with the right brain or any part of the right brain, neither with any single brain region, the prefrontal cortex excluded. It is unclear which parts of the prefrontal cortex are during creative cognition activated, or deactivated. It can be just concluded that creativity induces changes in prefrontal brain activity.

The same is true for the popular assumption that creativity is associated with low arousal, defocused attention, or alpha synchronization. The weight of the reviewed evidence simply does not support them.

\section{Can Ability Be Trained?}

Attempts to improve ability are by no means new in psychology. The main objective is to improve fundamental processes that form the basis of intelligent behavior and in that way increase general intelligence $(\mathrm{G})$, or fluid intelligence (Gf). It is of course very easy to increase test performance by simply practicing the tests themselves, or by practicing similar tasks. However, since Jensen's $[69,70]$ claim that interventions aiming to improve intelligence resulted in only very little if any success at all, only sporadic attempts have been made to investigate interventions that could increase ability. To mention just one, the highly controversial Mozart effect, an enhancement of performance or change in neurophysiological activity associated with listening to Mozart's Sonata K. 448 [71, 72].

Recently, the debate on whether certain interventions can increase ability has once more gained popularity. The discussion has been triggered by the study of Jaeggi and colleagues [73] showing that working memory (WM) training can increase fluid intelligence. Jaeggi et al. [73] have shown that an increase in fluid intelligence can be obtained by training on problems that, at least superficially, do not resemble those on the ability tests. They could further show that more training leads to greater IQ gains, which were present across the whole spectrum of abilities, although larger toward the lower end of the spectrum.

Buschkuehl and Jaeggi [74] in a review of 11 studies aimed at improving intelligence, divided the interventions used to influence ability into approaches that were focused 
on training of WM and executive functions, and interventions which entailed other approaches - video games and other cognitively stimulating activities, like music, or supplementing participants with creatine. Two conclusions have been put forward: First, most of the studies, are heterogeneous on several dimensions and have certain methodological shortcomings, yet most of them reported significant improvements in measures of ability. Second, most numerous were the attempts to improve intelligence by WM training tasks [75]. This seems reasonable as there is a strong link between WM and intelligence [76]. Further, there exist well elaborated models of WM, like the multi component model of Baddeley [77], or the embedded processes model proposed by Cowan [78]. The models do differ, but they define WM function as the combination of short-term storage and some sort of processing components. It is further worth mentioning that in a recent study by Colom [76] it could be shown that short-term storage largely accounted for the relationship between working memory and intelligence, and that processing components, like mental speed, updating, and the control of attention had a negligible, or no relation to intelligence.

A much less favorable view with respect to the trainability of ability was provided by Owen and colleagues [79]. In their large-scale study 11,430 individuals participated in a 6-week online training of different cognitive tasks designed to improve reasoning, memory, planning, visuo-spatial skills and attention. The findings led the authors to the conclusion that, although improvements were observed in every one of the cognitive tasks for which were trained, no evidence was found for transfer effects to untrained tasks, even when those tasks were cognitively closely related, or to any general improvement in the level of cognitive functioning.

The second strand of research, which is fostering the debate on the possibility of increasing the level of IQ, comes from the broad area of neuroscience. Until recently neurologists were convinced that neural plasticity is present only in childhood. Plasticity of the nervous system denotes developmental changes in synaptic density and synaptic pruning, and plays the key role in cell loss, and the growth and myelination of white matter [80]. There is also evidence that there is some plasticity and fine-tuning that continues across the lifespan. Maguire et al. [81] found that in London taxi-drivers the posterior region of the hippocampus is much larger than in the rest of the population, whereas the front region is much smaller. One important role of the hippocampus is to facilitate spatial memory in the form of navigation. Similarly, an enlargement of the auditory cortex $(25 \%)$ in highly skilled musicians compared with people who never played an instrument was reported by Pantev [82]. That such changes can be rather rapid was shown by Pascual-Leone [83]. Even the amount of five days practicing a five-finger piano exercise enlarged areas of the brain responsible for finger movements. On the other hand, when practicing stops, the brain tends to return to its normal size. This was shown by a study where people learned to juggle for three months. After training, an increase in size in the middle temporal area and the left posterior intra-parietal sulcus (areas responsible for visual motion information) was observed. Nonetheless, after 3 months of no practice, these areas returned to their previous size $[84,85]$.
In the light of these findings, one could expect that training aimed to increase intelligence, would be also reflected in brain functioning. Further support for this view was provided by several neurofeedback studies. The study by Keizer et al. [86] has shown that neurofeedback in the gamma-band (36-44 Hz) could improve episodic retrieving. In another study by Zoefel [87] neurofeedback training of the upper alpha frequency band improved cognitive performance on a mental rotation task. Egner and Gruzelier [88] could further show that learning to progressively raise theta $(5-8 \mathrm{~Hz})$ over alpha $(8-11 \mathrm{~Hz})$ band amplitudes significantly enhanced music performance. Several additional studies conducted by the author [89] showed the positive influence of theta/alpha neurofeedback on creativity and ballroom dancing.

\section{DISCUSSION}

This short review has shown that research into the braincognition relationship is characterized by mountains of data and weak theories. The theories are of rather low generality and explain only specific relationships. For instance, the efficiency theory explains only the brain-ability relationship; further, the explanation is adequate only when problem solving tasks as opposed to memory tasks are involved; in addition, it has a gender- by- task bias. The fact that intelligence tests represent from a psychometric perspective the most reliable measures of human psychological characteristics, renders biological explanations of other psychological characteristics, such as personality and creativity even less promising.

Despite, the diversity of research findings relating behavior with brain activity, there are still some implication for teaching. At a recent conference at the University of Cambridge on brain-based-learning [90] it was stressed that teachers receive a lot of oversimplified, and misrepresented information about brain-based-learning that allow for "neuro myths' to flourish. Teachers are told that the right brain is said to dominate in the processing of forms and patterns, spatial manipulation, rhythm, images, pictures and creativity, consequently they are advised to ensure that their classroom practice is 'left- and right-brain balanced', or more "rightbrain" oriented to foster creative performance. Such neuro myths must be stopped. One most potent mechanism to do that involves increasing scientific and cognitive neuroscience literacy amongst educators - a body of peer-reviewed literature and websites (e.g., http://www.teach-the-brain.org), that provides clear and accurate summaries of progress in the cognitive neuroscience of learning.

The speculation that creative cognition is domain specific, involving different cognitive processes, emotional states and personality types, would for teachers and educators suggest to provide children and students with highly diverse problem settings. We do not advocate hothousing of children, suggesting that they should begin the study of languages, advanced mathematics, logic, and music as early as possible. On the contrary, in our opinion education should provide children with problems that would maintain their natural curiosity - to work against the erosion of motivation. Research reveals that children's interest, enthusiasm, and intrinsic motivation for learning in school deteriorate continuously from their entry into kindergarten 
until they complete high school (or drop-out), with striking losses during the transitions to middle and high school [91].

The most urgent task in front of creativity researchers is to develop ecological valid measures of creative cognition. A problem that has been put forward by both review articles discussed in the previous section, and led Dietrich and Kanso [61, p. 834] ask the question: "Can we really expect to identify the Michelangelos and Curies of tomorrow by how many innovative uses they can come up with for a brick?"

In our view the most promising approach would be to compare thinking processes of artists, musicians and scientists while involved in creative problem solving in their domain and another unfamiliar domain. For instance, creative cognition of a musician while composing and while trying to write a poem. To our knowledge, there are no studies which have made such a comparison. Studies employing the artistic paradigm of creativity research have either investigated the creative processes of artists while performing tasks in the domain of their expertise - jazz pianists improvisation of novel melodic, harmonic, and rhythmic music [92]; designers to design a new pen [93], or have compared the creative process of experts (professional artists) with mental processes of novices in a specific domain (e.g., professional dancers and novices were asked to mentally perform a dance) [94].

From an educational perspective it would be worthy to study the trainability of creative processes - the pattern of training induced changes in brain activity. A first step in this direction represents a recent study by Fink and colleagues [95]. In this fMRI study, it was investigated whether creative cognition can be enhanced through idea sharing and how performance improvements are reflected in brain activity. Further research should extend to more domain-specific creativity training approaches in class-room settings combining neurofeedback with cognitive training.

\section{ACKNOWLEDGEMENT}

None declared.

\section{CONFLICT OF INTEREST}

None declared.

\section{REFERENCES}

[1] Skinner BF. The science of learning and the art of teaching. Harv Educ Rev 1954; 24(1): 86-97.

[2] Bruner JS. Beyond the information given. New York, NY: W. W. Norton \& Company Inc. 1973.

[3] Vygotskij LS. Mind and society. Cambridge, MA: Harvard University Press 1978.

[4] Bruer JT. Education and the brain: a bridge to far. Educ Res 1997; 26(3): 4-16.

[5] Hunt NP. Designing instruction for the Web: Incorporating new conceptions of the learning process. Proceedings of the $10^{\text {th }}$ World Conference on Educational Multimedia and Hypermedia \& World Conference on Educational Telecommunication (ED-MEDIA/EDTELECOM 98), Freiburg, Germany; June 20-25,1998, pp. 334-42.

[6] Blakemore SJ, Frith U. The learning brain: lessons for education. Oxford, UK: Blackwell 2005.

[7] Goswami U. Neuroscience and education: from research to practice. Nature Reviews Neuroscience 7(5): doi:10.1038/nrn1907. Retrieved 2006 May 7, from: http://www.nature.com/reviews/ neuro

[8] Posner MI, Rothbart MK. Influencing brain networks: implications for education. Trends Cogn Sci 2005 9(3): 99-103.
[9] Fischer KW, Daniel DB, Immordino-Yang MH, Stern E, Battro A, Koizumi H. Why mind, brain, and education? Why now? Mind Brain Educ 2007; 1(1): 1-2.

[10] Pavlov IP. Complete collected works. Moscow, Izd: AU SSSR 1949.

[11] Jung RE, Haier RJ. The Parieto-Frontal Integration Theory (P-FIT) of intelligence: Converging neuroimaging evidence. Behav Brain Sci 2007; 30(2): 135-87.

[12] Thorndike EL. Intelligence and its use. Harper's Mag 1920; 140(12): 227-35

[13] Mayer JD, Salovey P, Caruso DR. Mayer-Salovey-Caruso emotional intelligence test (MSCEIT). Toronto: MHS 2002.

[14] Neubauer AC, Fink A. Intelligence and neural efficiency. Neurosci Biobehav Rev 2009; 33(7): 1004-23.

[15] Haier RJ, Benbow CP. Sex differences and lateralization in temporal lobe glucose metabolism during mathematical reasoning. Dev Neuropsychol 1995; 11(4): 405-14.

[16] Jaušovec N. Differences in EEG alpha activity related to giftedness. Intelligence 1996; 23(3): 159-73.

[17] Lutzenberger W, Elbert T, Birbaumer N, Ray WJ. The scalp distribution of the fractal dimension of the EEG and its variation with mental tasks. Brain Top 1992; 5(1): 27-34.

[18] Neubauer V, Freudenthaler HH, Pfurtscheller G. Intelligence and spatiotemporal patterns of event-related desynchronization. Intelligence 1995; 20(3): 249-66.

[19] Jaušovec N, Jaušovec K, Gerlič I. Differences in event related and induced EEG patterns in the theta and alpha frequency bands related to human emotional intelligence. Neurosci Lett 2001; 311(2): 93-6.

[20] Jaušovec $\mathrm{N}$, Jaušovec $\mathrm{K}$. Sex differences in brain activity related to general and emotional intelligence. Brain Cogn 2005; 59(3): 27786.

[21] Jaušovec N, Jaušovec K. Differences in induced gamma and upper alpha oscillations in the human brain related to verbal/performance and emotional intelligence. Int J Psychophysiol 2005; 56(3): 223-5.

[22] Haier RJ, White NS, Alkire MT. Individual differences in general intelligence correlate with brain function during nonreasoning tasks. Intelligence 2003; 31(5): 429-41.

[23] Jaušovec N, Jaušovec K. Spatiotemporal brain activity related to intelligence: a low resolution brain electromagnetic tomography study. Cogn Brain Res 2003; 16(2): 267-72.

[24] Gevins A, Smith M.E. Neurophysiological measures of working memory and individual differences in cognitive ability and cognitive style. Cereb Cortex 2000; 10(9): 830-9.

[25] Jaušovec N, Jaušovec, K. Differences in induced brain activity during the performance of learning and working-memory tasks related to intelligence. Brain Cogn 2004; 54(1): 65-74.

[26] Doppelmayr M, Klimesch W, Hödlmoser K, Sauseng P, Gruber W. Intelligence related upper alpha desynchronization in a semantic memory task. Brain Res Bull 2005; 66(2): 171-7.

[27] Neubauer AC, Fink A, Schrausser DG. Intelligence and neural efficiency: The influence of task content and sex on the brain - IQ relationship. Intelligence 2002; 30(6): 515-36.

[28] Neubauer AC, Fink A. Fluid intelligence and neural efficiency: effects of task complexity and sex. Pers Individ Diff 2003; 35(4): 811-27.

[29] Neubauer AC, Grabner RH, Fink A, Neuper C. Intelligence and neural efficiency: further evidence of the influence of task content and sex on the brain-IQ relationship. Cogn Brain Res 2005; 25(1): 217-25.

[30] Fink A, Neubauer AC. EEG alpha oscillations during the performance of verbal creativity tasks: differential effects of sex and verbal intelligence. Int J Psychophysiol 2006; 62(1): 46-53.

[31] Jaušovec N, Jaušovec $K$. Spatial-rotation and recognizing emotions: Gender related differences in brain activity. Intelligence 2008; 36(5): 383-93.

[32] Duncan J. An adaptive coding model of neural function in prefrontal cortex. Nat Rev Neurosci 2001; 2(11): 820-9.

[33] Colom R, Haier RJ, Head K, Álvarez-Linera J, Quiroga M, Chun SP. Gray Matter Correlates of Fluid, Crystallized, and Spatial Intelligence: Testing the P-FIT Model. Intelligence 2009; 37(2): 124-35.

[34] Haier RJ, Colom R, Schroeder DH, Condon CA, Tang C, Eaves E, Head K. Gray matter and intelligence factors: Is there a neuro-g? Intelligence $2009 ; 37(2): 136-44$. 
[35] Eysenck HJ. The biological basis of personality. Springfield, IL: Thomas 1967.

[36] Gray JA. Neural systems, emotion and personality. In: Madden IV J, Ed. Neurobiology of learning, emotion and affect. New York: Raven Press 1991.

[37] Eysenck HJ, Eysenck MW. Personality and individual differences. New York: Plenum 1985.

[38] Gale A. The psychophysiology of individual differences: studies of extraversion and the EEG. In: Kline P, Ed. New approaches in psychological measurement. London: Wiley. 1973, pp. 211-56.

[39] Eysenck HJ. Personality: Biological foundations. In: Vernon PA, Ed. The neuropsychology of individual differences. London: Academic Press 1994.

[40] Eysenck HJ. Biological dimensions of personality. In: Pervin LA, Ed. Handbook of personality: theory and research. New York: Guilford Press 1990, pp. 244-70.

[41] Gale A. Electroencephalographic studies of extraversion-introversion: A case study in the psychophysiology of individual differences. Pers Individ Diff 1983; 4(2): 371-80.

[42] O'Gorman JG. Extraversion and the EEG: I. An evaluation of Gale's hypothesis. Biol Psychol 1984; 19(2): 95-112.

[43] Zuckerman M, Kuhlman DM, Joireman J, Teta P, Kraft M. A comparison of three structural models for personality: the big three, the big five, and the alternative five. J Person Soc Psychol 1993; 65(4): 757-68.

[44] Matthews G, Gilliland K. The personality theories of H. J. Eysenck and J. A. Gray: a comparative review. Pers Individ Diff 1999; 26(4): 583-626.

[45] Fink A, Schrausser DG, Neubauer, AC. The moderating influence of extraversion on the relationship between IQ and cortical activation. Pers Individ Diff 2002; 33(2): 311-26.

[46] Fink A, Neubauer AC. Extraversion and cortical activation: effects of task complexity. Pers Individ Diff 2004; 36(2): 333-47.

[47] Matthews G, Amelang M. Extraversion, arousal theory and performance: a study of individual differences in the EEG. Pers Individ Diff 1993; 14(2): 347-63.

[48] Smith BD, Kline R, Lindgren K, Ferro M, Smith DA, Nespor A. The lateralized processing of affect in emotion-ally labile extraverts and introverts: central and autonomic effects. Biol Psychol 1995; 39(2-3): 143-57.

[49] Schmidtke JI, Heller W. Personality, affect and EEG: predicting patterns of regional brain activity related to extraversion and neuroticism. Pers Individ Diff 2004; 36(3): 717-32.

[50] Gale A, Edwards JA, Morris P, Moore R, Forrester D. Extraversion-introversion, neuroticism-stability, and EEG indicators of positive and negative empathic mood. Pers Individ Diff 2001; 30(3): 449-61.

[51] Tran Y, Craig A, McIsaac P. Extraversion-introversion and 8-13 $\mathrm{Hz}$ waves in frontal cortical regions. Pers Individ Diff 2001; 30(2): $205-15$.

[52] Knyazev GG, Slobodskaya HR, Wilson GD. Psychophysiological correlates of behavioural inhibition and activation. Pers Individ Diff 2002; 33(4): 647-60.

[53] Knyazev GG, Slobodskaya HR, Safronova MV, Sorokin OV, Goodman R, Wilson GD. Personality, psychopathology and brain oscillations. Pers Individ Diff 2003 35(6): 1331-49.

[54] Stough C, Donaldson C, Scarlata B, Ciorciari J. Psychophysiological correlates of the NEO PI-R Openness, Agreeableness and Conscientiousness: preliminary results. Int J Psychophysiol 2001; 41(1): 87-91.

[55] Tran Y, Craig A, Boord P, Connell K, Cooper N, Gordon E. Personality traits and its associations with resting regional brain activity. Int J Psychophysiol 2006; 60(3): 215-24.

[56] Jaušovec N, Jaušovec K. Personality, gender and brain oscillations. Int J Psychophysiol 2007; 66(3): 215-24.

[57] Jaušovec $N$, Jaušovec $K$. A typology of human neuro-electric brain activity and its relation to personality and ability. Richerche di Psichologia 2011; in press.

[58] DeYoung CG, Petersonn JB, Higgins DM. Higher-order factors of the Big Five predict conformity: Are there neuroses of health? Pers Individ Diff 2002; 33(4): 533-52.

[59] Musek J. A general factor of personality: evidence for the Big One in the five-factor model. J Res Pers 2007; 41(6): 1213-33.

[60] Villalba E. Monitoring Creativity at an Aggregate Level: a proposal for Europe. Eur J Educ 2010; 45(2): 314-30.
[61] Dietrich A, Kanso R. A Review of EEG, ERP, and Neuroimaging Studies of Creativity and Insight. Psychol Bull 2010; 136(5): 82248.

[62] Bontje M, Musterd S. Creative industries, creative class and competitiveness: Expert opinions critically appraised. Geoforum 2009; 40(5): 843-852.

[63] Wertheimer M. Productive thinking. New York: Harper \& Row 1945

[64] Arden R, Chavezb RS, Grazioplene R, Jung RE. Neuroimaging creativity: a psychometric view. Behav Brain Res 2010; 214(2): 143-56.

[65] Guilford JP. Creativity. Am Psychol 1950; 5(9), 444-54.

[66] Dietrich A. Who's afraid of a cognitive neuroscience of creativity? Methods 2007 42(1): 22-7.

[67] Wallas G. The art of thought. London: Watts 1926.

[68] Jaušovec $N$, Jaušovec $K$. Emotional intelligence and gender: A neurophysiological perspective. Paper presented at the 15th European Conference on Personality, Brno, July 20-24, 2010.

[69] Jensen AR. How much can we boost IQ and scholastic achievement? Harv Educ Rev 1969 39(2): 1-123.

[70] Jensen AR. Raising the IQ: The Ramey and Haskins study. Intelligence 1981; 5(1): 29-40.

[71] Rauscher FH, Shaw GL, Ky KN. Music and spatial task performance. Nature 1993; 365(6447): 611.

[72] Pietschnig J, Voracek M, Forman AM. Mozart effect-Schmozart effect: A meta-analysis. Intelligence 2010; 38(3): 314-23.

[73] Jaeggi SM, Buschkuehl M, Jonides J, Perrig WJ. Improving fluid intelligence with training on working memory. Proc Natl Acad Sci USA 2008; 105(19): 6829-33.

[74] Buschkuehl M, Jaeggi SM. Improving intelligence: a literature review. Swiss Med Wkly 2010; 140(19-20): 266-72.

[75] Klingberg T. Training and plasticity of working memory. Trends Cogn Sci 2010; 14(7): 317-24

[76] Colom R, Abad FJ, Quiroga M, Chun SP, Flores-Mendoza C. Working memory and intelligence are highly related constructs, but why? Intelligence 2008; 36(6): 584-606.

[77] Repovš G, Baddeley A. The multi-component model of working memory: explorations in experimental cognitive psychology. Neuroscience 2006; 139(1): 5-21.

[78] Cowan N. An embedded-processes model of working memory. In: Miyake A, Shah P, Eds. Models of working memory. Cambridge: Cambridge University Press 1999, pp. 62-101.

[79] Owen AM, Hampshire A, Grahn JA, et al. Putting brain training to the test. Nature 2010; 465(7229): 775-9.

[80] Craik FIM. Brain-behavior relations across the lifespan: A commentary. Neurosci Biobehav Rev 2006; 30(6): 885-92.

[81] Maguire EA, Gadian DG, Johnsrude IS, et al. Navigation-related structural change in the hippocampi of taxi drivers. Proc Natl Acad Sci USA 2000; 97(8): 4398-403.

[82] Pantev C, Ross B, Fujioka T, Trainor LJ, Schulte M, Schultz M. Music and learning-induced cortical plasticity. Am N Y Acad Sci 2003; 999: 438-50.

[83] Pascual-Leone A. The brain that plays music and is changed by it. Ann N Y Acad Sci 2001; 930, 315-29.

[84] Draganski B, Gaser C, Busch V, Sheerer G, Bogdahn U, May A. Neuroplasticity: changes in grey matter induced by training. Nature 2004; 427(6972): 311-2.

[85] Driemeyer J, Boyke J, Gaser C, Büchel C, May A. Changes in Gray Matter Induced by Learning-Revisited. PLoS One 2008; 3(7): e2669.

[86] Keizer AW, Verment RS, Hommel B. Enhancing cognitive control through neurofeedback: A role of gamma-band activity in managing episodic retrieval. NeuroImage 2010; 49(4): 3404-13

[87] Zoefel B, Huster RJ, Herrmann CS. Neurofeedback training of the upper alpha frequency band in EEG improves cognitive performance. NeuroImage 2011; 54(2): 1427-31.

[88] Egner T, Gruzelier HJ. Ecological validity of neurofeedback: modulation of slow wave EEG enhances musical performance. Neuroreport 2003; 14(9): 1221-4.

[89] Gruzelier J. A theory of alpha/theta neurofeedback, creative performance enhancement, long distance functional connectivity and psychological integration. Cogn Process 2009; 10 (Suppl 1) S101-S109.

[90] Economic and Social Research Council Teaching and Learning Research Programme (ESRC TLRP) seminar series. Collaborative Frameworks for Neuroscience and Education. Education and Brain 
Research: Neuroscience, Teaching and Learning Conference. 2527 July 2005, Faculty of Education, University of Cambridge, UK; 2005. Retrieved 2005 July 25, from: http://www.tlrp.org/pub/doc uments/Neuroscience\%20Commentary\%20FINAL.pdf

[91] Wigfield A, Eccles JS, Schiefele U, Roeser R, Davis-Keane P. Development of achievement motivation. In: Damon W, Eisenberg N, Eds. Handbook of child psychology, $6^{\text {th }}$ ed. Social, emotional and personality development. NY: Wiley 2006; vol 3: pp. 9331002 .
[92] Limb C, Braun A. Neural substrates of spontaneous musical performance: An fMRI study of jazz improvisation. PLoS One 2008; 3(2): e1679.

[93] Kowatari Y, Lee S, Yamamura H, et al. Neural networks involved in artistic creativity. Hum Brain Map 2009; 30(5): 1678-90.

[94] Fink A, Graif B, Neubauer AC. Brain correlates underlying creative thinking: EEG alpha activity in professional $v s$ novice dancers. NeuroImage 2009; 46(3): 854-62.

[95] Fink A, Grabner RH, Gebauer D, Reishofer G, Koschutnig K, Ebner F. Enhancing creativity by means of cognitive stimulation: evidence from an fMRI study. NeuroImage 2010; 52(4): 1687-95.

(C) Jaušovec and Jaušovec; Licensee Bentham Open.

This is an open access article licensed under the terms of the Creative Commons Attribution Non-Commercial License (http://creativecommons.org/licenses/by-nc/ 3.0/) which permits unrestricted, non-commercial use, distribution and reproduction in any medium, provided the work is properly cited. 